\title{
Improving the outcomes of children affected by parental substance abuse: a review of randomized controlled trials
}

This article was published in the following Dove Press journal:

Substance Abuse and Rehabilitation

28 January 2015

Number of times this article has been viewed

\section{Stacy Calhoun ${ }^{1,2}$ \\ Emma Conner ${ }^{2}$ \\ Melodi Miller ${ }^{3}$ \\ Nena Messina'}

'UCLA Integrated Substance Abuse Programs, Los Angeles, CA, USA;

${ }^{2}$ Department of Criminology, Law and Society, University of California, Irvine, CA, USA; ${ }^{3}$ Social Solutions International, Inc., Silver Spring, MD, USA
Correspondence: Stacy Calhoun UCLA Integrated Substance Abuse Programs, I I 075 Santa Monica Blvd, Suite 100, Los Angeles, CA, USA

$\mathrm{Tel}+\mathrm{I} 3102675502$

Fax + I 3103120559

Email scalh@ucla.edu
Abstract: Substance abuse is a major public health concern that impacts not just the user but also the user's family. The effect that parental substance abuse has on children has been given substantial attention over the years. Findings from the literature suggest that children of substance-abusing parents have a high risk of developing physical and mental health and behavioral problems. A number of intervention programs have been developed for parents who have a substance abuse problem. There have also been a number of interventions that have been developed for children who have at least one parent with a substance abuse problem. However, it remains unclear how we can best mitigate the negative effects that parental substance abuse has on children due to the scarcity of evaluations that utilize rigorous methodologies such as experimental designs. The purpose of this study is to review randomized controlled trials of intervention programs targeting parents with substance abuse problems and/or children with at least one parent with a substance abuse problem in order to identify programs that show some promise in improving the behavioral and mental health outcomes of children affected by parental substance abuse. Four randomized controlled trials that met our eligibility criteria were identified using major literature search engines. The findings from this review suggest that interventions that focus on improving parenting practices and family functioning may be effective in reducing problems in children affected by parental substance abuse. However, further research utilizing rigorous methodologies are needed in order to identify other successful interventions that can improve the outcomes of these children long after the intervention has ended.

Keywords: RCT, family, interventions

\section{Introduction}

Substance abuse is a major public health concern that has impacts not only on the user but also the user's family. This is especially true for children exposed to parental substance abuse in the home environment. Findings from the 2009 National Survey on Drug Use and Health (NSDUH) showed that a little over 8.3 million children under the age of 18 years have lived with at least one parent who abused illicit drugs or alcohol during the 12 months prior to being interviewed for the survey. ${ }^{1}$ These children are at increased risk for a variety of problems, such as abuse and neglect, which can negatively impact their physical and emotional well-being. ${ }^{2}$ In addition, parental substance abuse has been linked to ongoing behavioral problems, such as adolescent drug use. ${ }^{3}$ Thus, it is important to find ways to mitigate the negative impact that parental substance abuse has on the developmental outcomes of the children affected by this issue. The purpose of this review is to identify interventions targeting parents with a substance abuse problem and/or children who have at least one parent with a 
substance abuse problem that have been shown to improve at least one child outcome (eg, drug use, mental health, and behavioral problems) in a randomized controlled trial. A brief overview of the research outlining the consequences that parental substance abuse can have on children is provided, followed by a review of the promising interventions that appear to improve outcomes of children affected by parental substance abuse. We conclude the paper by discussing areas that need further research and potential interventions drawn from the Blueprint registry of evidence-based programs that may be effective in reducing problems among children of substance-abusing parents.

\section{Prenatal effects of parental substance use}

It has been estimated that approximately 225,000 infants are prenatally exposed to their mothers' use of illicit substances each year, ${ }^{4}$ and exposure to these substances is often the first point in which children experience the negative effects of parental substance abuse. Physiological manifestations of this exposure may include low birth weight, feeding difficulties, increased irritability by the infant, and stunted cognitive and physical development. ${ }^{5}$ The severity and nature of these manifestations vary depending on the illicit substance used, as well as the frequency and duration of use. For example, children exposed to methamphetamine use have been found to be at increased risk of being small for their gestational age and exhibit low arousal, poor quality of movement, and increased physiological stress. ${ }^{6-8}$ In contrast, prenatal opioid use has been shown to lead to neonatal abstinence syndrome, in which infants experience opioid withdrawal symptoms after birth as a result of no longer being exposed to the substance. ${ }^{9}$ Problems resulting from prenatal exposure to other drugs may not manifest themselves until later in the child's development. For example, prenatal cocaine exposure has been associated with poor language development, 5,10 emotional problems (eg, social withdrawal, anxiety, and depression), and negative behavioral manifestations (eg, delinquency, aggressiveness, and pre-teen substance abuse). ${ }^{11,12}$

\section{Parental substance abuse in the home}

The impact of parental substance abuse on the functioning of the family can be particularly severe, especially as it relates to parenting practices and the care of children. ${ }^{13}$ Studies have shown a strong association between improper parenting practices and subsequent negative behavioral manifestations such as delinquency. ${ }^{14,15}$ These improper parenting practices take the form of harsh discipline such as spanking or threatening a child in response to problematic behavior. ${ }^{15,16}$ The evidence further suggests that parents who engage in substance abuse are also more likely to engage in these problematic parenting practices than those who do not. Hien and Honeyman ${ }^{17}$ found that among a sample of low-income mothers receiving treatment at a public hospital, those who abused crack or cocaine were significantly more likely than mothers who did not to endorse the use of harsh disciplinary practices, which included the use of corporal punishment techniques (eg, hitting the child with a belt). Similarly, Fals-Stewart et al ${ }^{18}$ found that fathers who engaged in substance abuse had lower scores on the Parental Monitoring Scale ${ }^{19}$ and were more likely to engage in more dysfunctional disciplinary practices as measured by the Parenting Scale ${ }^{20}$ than fathers who did not. Additionally, in a study that examined the relationship between specific parenting practices in families with at least one substance-abusing parent, Stanger et $\mathrm{al}^{14}$ found that inconsistent application of discipline predicted rule breaking, aggression, and attention problems.

Parental substance abuse can leave children at risk of being neglected whereby the parents fail to take care of their basic needs, such as being fed and properly clothed. ${ }^{21}$ Findings from the literature suggest that children of methamphetamine users and manufacturers are especially vulnerable to neglect. Messina and Jeter ${ }^{22}$ examined 99 cases of children who were removed from home-based methamphetamine labs in Los Angeles County from 2001-2003, and found that 94\% of the allegations of child neglect among this sample were substantiated by a Child Protective Services case worker. Children who live in homes where methamphetamine labs exist are not only exposed to the drug itself, but often live in unsanitary environments characterized by the presence of animal feces, ticks, cockroaches, garbage, and drug paraphernalia, ${ }^{22-24}$ and are at high risk of ingesting food that is spoiled, rotten, or contaminated with chemicals. ${ }^{23}$

The association between child neglect and problematic behaviors has been well-established. ${ }^{25}$ However, establishing the underlying mechanisms that explain the nature of this relationship is difficult due to the fact that families with at least one parent who abuses drugs often experience a range of problems (eg, mental illness or chronic unemployment) that can undermine the parent's ability to care for their children and increase their risk of becoming involved with child welfare services. ${ }^{26}$ Child neglect is the most common reason for involvement with child welfare services, and it has been estimated that $50 \%-80 \%$ of children removed from homes due to neglect and involved in the child welfare system have at least one substance-abusing parent. ${ }^{27}$ However, while the 
evidence surrounding the long-term effects of foster care placement on child outcomes is mixed, some of this evidence points to the negative effects that placement instability has on child development. ${ }^{28,29}$ As such, there are many who advocate for more emphasis on intervention and family preservation.

\section{Incarceration}

In addition to parental separation as a result of child protective services involvement, parental separation is also a result of a substance-abusing parent being incarcerated. Between 1996 and 2006, the number of adults incarcerated for a drugrelated offense increased by $43 \%$, to 1.9 million, as a result of the harsh policies associated with the War on Drugs. ${ }^{30}$ A substantial proportion of those incarcerated were parents of minor children. One report estimated that in 2006, there were 1 million parents with 2.2 million minor children who were housed in America's prisons and jails for drug-related offenses. ${ }^{30}$ Given the number of children who have lost substance-abusing parents to incarceration, it is important to understand the behavioral, emotional, social, academic, and financial impact that incarceration may have on children.

There is substantial evidence in the literature that parental incarceration is associated with various negative outcomes for children. Children of incarcerated parents are more likely to exhibit conduct disorders and other delinquent behavior than their peers. ${ }^{31}$ For adolescent males in particular, parental incarceration has been shown to be associated with an increase in theft and marijuana use. ${ }^{32,33}$ Teachers report observing more negative, disruptive behaviors in the classroom among children whose parents are incarcerated and fewer positive, pro-social behaviors. ${ }^{34}$ There is also evidence that adolescent boys are more likely to drop out of high school, particularly when the mother is the incarcerated parent and the incarceration begins during the child's early adolescence. ${ }^{35}$ In addition, a 12 -year longitudinal study found that Chicago Public School children who had at least one incarcerated parent had standardized test scores that were, on average, lower than students whose parents were not incarcerated. ${ }^{36}$

Parental incarceration can affect the socioemotional development of children. Among the children of incarcerated women, girls are more likely to exhibit low self-esteem, anxiety, and depression compared to boys, especially when the mother has been sentenced to a lengthy incarceration. ${ }^{37}$ Socially, both boys and girls suffer from self-imposed isolation because of the stigma associated with parental incarceration, even in neighborhoods in which incarceration is presumed to be the norm. In addition, children often self-report a feeling of premature adulthood, acting as a mediator between their designated caregiver and their incarcerated parent, or assuming for themselves the role of caregiver for the nonincarcerated parent. ${ }^{38}$

While it is certain that some children benefit from the removal by incarceration of a dangerous, abusive, or unstable parent, it is also possible that parental incarceration may result in certain disadvantages to children, such as poverty and lack of access to resources. ${ }^{39}$ Even in cases where the incarcerated parent (usually the father) was not living with the child prior to incarceration, that parent may have been contributing to the child's financial well-being via both legal and illegal means. Upon release from incarceration, many parents have difficulty securing legitimate employment and resuming financial support for their children. ${ }^{40}$ Thus, the negative consequences that incarceration can have on the financial stability of the family can often last long after the parent has been released.

\section{Methods}

A review of the literature was performed using PsychINFO, PubMed, and the Cochrane database of controlled trials to identify randomized controlled trials of interventions that have been directed at either parents with a substance abuse problem (this includes both drugs and alcohol) and/or children with at least one parent with a substance abuse problem. Search terms included "parents", "mother", "father", "child", "infant", "prenatal", "substance abuse", "substance dependence", "addiction", "substance use", "drug abuse”, "drug dependence", "drug use", "alcohol use", "alcohol abuse", "alcohol dependence", "treatment", and "intervention". Search terms were used in combination as well as with the limits "randomized controlled trial", "randomized", or "randomly assigned". Review articles were also obtained and the references scanned for further randomized controlled trials. Studies were included in this review if all of the following criteria were met: 1) all of the study participants were parents who had a substance abuse problem (includes alcohol) and/or children under the age of 18 who had at least one parent who had a substance abuse problem; 2) study participants were randomly assigned to a treatment group; 3 ) the duration of the participant follow-up was at least 6 months after the completion of the intervention; 4) the study was published in English; 5) participants who dropped out of the program were not excluded in the analyses; and 6) the intervention was effective in improving at least one child outcome during the postintervention follow-up period.

In order to facilitate our summary and comparison of studies, effect sizes were reported for the programs identified 
in this review where possible. If the effects sizes were reported in the article, we used the effect sizes that were calculated by the authors. Otherwise, we calculated the effect size as Cohen's $d$ if there was enough data to do so. While we are reporting different effect size estimators (ie, $r, d$, and odds ratio [OR]) in this review, effect sizes will be evaluated according to the classification proposed by Cohen: ${ }^{41}$ small (0.20-0.49), medium (0.50-0.79), and large ( $\geq 0.80)$.

\section{Results}

In total, 288 articles were retrieved and coded for eligibility. Only four studies met all of the criteria for inclusion in this review. These studies were randomized controlled trials of interventions that targeted families where at least one parent had a substance abuse problem. The interventions were designed to not only reduce drug and alcohol use but also to improve overall family functioning by addressing and overcoming problems in the relationship of the parents as well as providing parenting skills training. All of the studies included in this review are listed in Table 1 and discussed in more detail below. ${ }^{42-45}$

\section{Parents under pressure}

Dawe and Harnett ${ }^{42}$ conducted a randomized controlled trial of the Parents under Pressure (PUP) intervention in Australia. PUP is a home-based treatment intervention that is delivered on a weekly basis over a period of 3-4 months. During the weekly sessions, parents are taught skills to help them with child management and how to build solid relationships with their children and with their partners. Participants in the program are also taught how to gain greater control over their emotional state and reduce the likelihood that they will relapse to drug or alcohol use. Additional case management was also provided to the PUP participants on an as-needed basis. A total of 64 families were randomized into either the PUP group, the brief intervention group, or the standard treatment group. The participants in the PUP group received the PUP intervention described above. Participants assigned to the brief intervention group received two sessions of parent training delivered by therapists in the clinic. Participants assigned to the standard treatment group received the regular treatment that was provided by the methadone clinic. Findings from the randomized controlled trial found that families assigned to the PUP program had a significantly greater improvement in family functioning and a significantly decreased likelihood of child abuse compared to families assigned to receive either the brief intervention or the standard methadone treatment. Additionally, the children of PUP participants had significantly greater reductions in problem behaviors over time as measured by the Strengths and Difficulties Questionnaire, which includes the subscales of emotional symptoms, conduct problems, hyperactivity, peer problems, and pro-social behavior. ${ }^{46,47}$

\section{Focus on families}

Catalano et $\mathrm{al}^{48}$ evaluated a family-based methadone treatment program called Focus on Families (FOF; now known as "Families Facing the Future") in order to assess the effectiveness of this program in reducing parental drug use, improving family communication and management practices (including unclear rules, poor monitoring of behavior, and inconsistent or harsh discipline), reducing family conflict, and reducing child problem behaviors during the 12-month period following the intervention. Parents participating in this study were randomly assigned to receive either the FOF program or standard methadone treatment. In addition to the standard methadone treatment, the FOF program included parenting skills training and home-based case management services. The parenting skills training consisted of 53 sessions of training that were delivered in a group setting with 6-10 families. The children took part in 12 of the sessions to allow the parents to practice using new parenting skills. Findings from this initial evaluation revealed that, compared to standard methadone treatment, the FOF program was significantly more effective in reducing parental drug abuse and improving parenting skills during a 12-month follow-up period. With regard to outcomes among the children, there were no significant differences in drug use and delinquency between children of parents assigned to the FOF and the children of parents assigned to standard methadone treatment. However, the trends favored the children with parents assigned to the FOF group. Furthermore, findings from the 12-year follow-up of this sample found that the male children of the FOF participants had a significantly reduced risk of developing a substance abuse disorder compared to male children of parents assigned to standard methadone treatment. This reduction in the risk of developing a substance use disorder among the FOF male children was associated with a medium effect size $(\mathrm{OR}=0.53)$. There were no significant differences in drug use among the female children. ${ }^{43}$

\section{Behavioral couples therapy}

Kelley and Fals-Stewart ${ }^{44}$ evaluated a Behavioral Couples Therapy (BCT) intervention for men who were receiving outpatient treatment for alcohol and drug abuse in order to determine whether the BCT intervention was effective in 


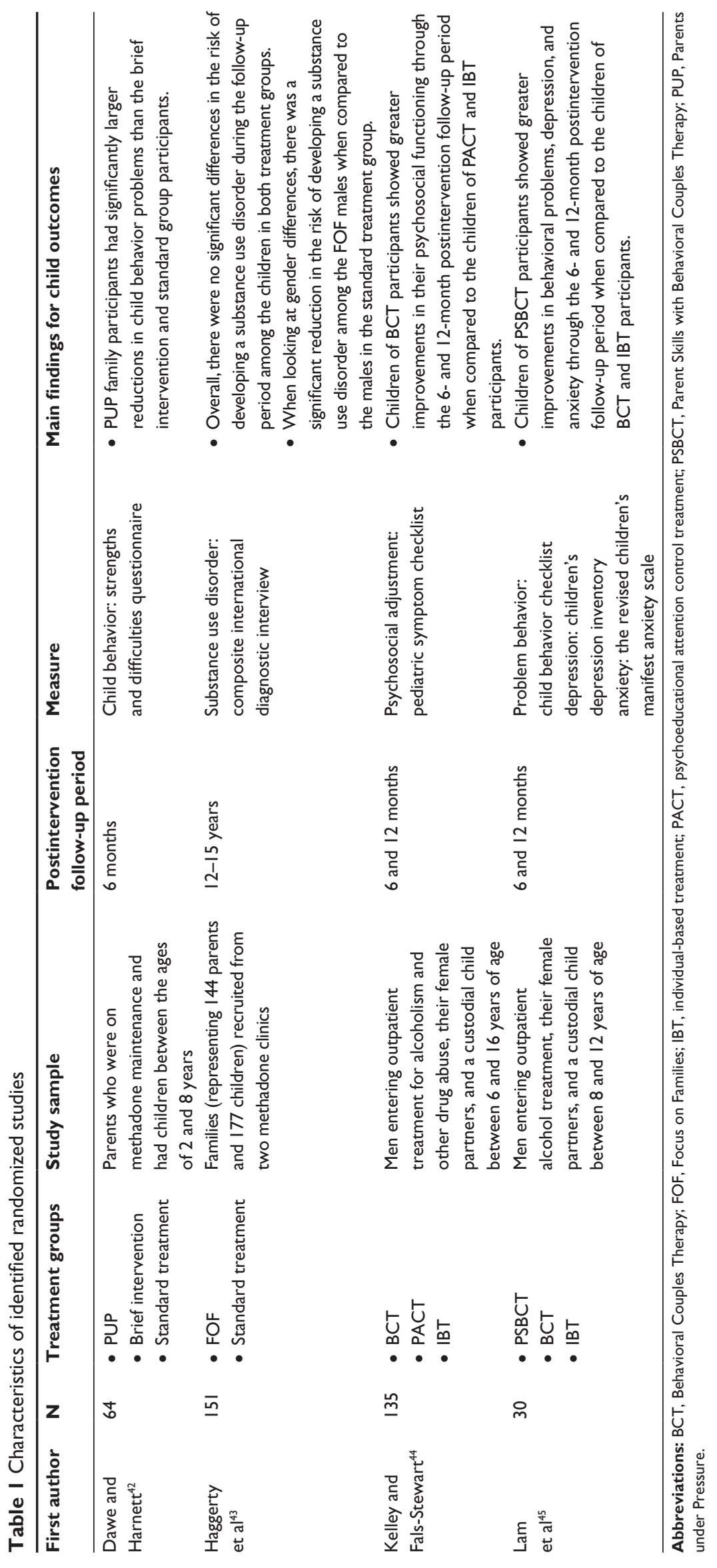


improving the psychosocial functioning of the participant's children. A total of 135 men were enrolled in the study. The men in this study had to be either married for at least 1 year or living with a significant other for at least 2 years. They also had to have at least one child living in their household. The men were randomly assigned to either BCT, individualbased treatment (IBT), or couples-based psychoeducational attention control treatment (PACT). Participants in all of the groups were expected to attend 32 treatment sessions. Participants in the IBT group attended all of their treatment sessions by themselves. Participants in the PACT group attended 20 individual-based sessions followed by 12 sessions that included their significant other. However, their significant other did not actively participate in the treatment sessions. In contrast, the significant other of the BCT participant actively participated in the 12 BCT treatment sessions that covered effective communication skills, positive behavioral exchanges between partners, and tools for eliminating verbal and physical aggression between partners. Mothers and fathers in all of the groups rated their child's psychosocial functioning using the Pediatric Symptom Checklist. ${ }^{49}$

The findings revealed that the children of the BCT participants had significantly better psychosocial functioning scores than the children of PACT and IBT participants throughout the 6- and 12-month postintervention follow-up period. Among the substance-abusing couples in the sample, small effect sizes were found for BCT couples at both the 6-month follow-up $(d=0.38)$ and 12-month follow-up $(d=0.42)$ when compared to IBT couples. Likewise, small effect sizes were found for the BCT drug-abusing couples at the 6-month follow-up $(d=0.32)$ and the 12-month follow-up ( $d=0.30)$ when compared to the PACT drug-abusing couples. Among the alcohol-abusing couples in the sample, small effect sizes were also found for the BCT couples at both the 6-month follow-up $(d=0.46)$ and the 12-month follow-up ( $d=0.26)$ when compared to the IBT couples. A medium effect was found for the BCT alcohol-abusing couples at the 6-month follow-up $(d=0.50)$ when compared to PACT couples. However, this effect size was not sustained at the 12-month follow-up, where a small effect size was observed for the BCT alcohol-abusing couples $(d=0.37)$ when compared to the PACT couples.

\section{Parent skills with behavioral couples therapy}

Lam et $\mathrm{al}^{45}$ conducted a study to assess whether adding a parenting component to BCT would enhance the positive child outcomes found in the previous evaluation of BCT discussed above. ${ }^{44}$ In this study, 30 men entering outpatient treatment were randomly assigned to one of three treatment groups: IBT, standard BCT, and Parent Skills with Behavioral Couples Therapy (PSBCT). Similar to the previous study, the men in this study had to be either married for at least 1 year or living with a significant other for at least 2 years. They also had to have at least one child living in their household. Participants assigned to the BCT treatment group received 12 standard BCT sessions, which included both partners. Participants assigned to the PSBCT group attended eight sessions of the standard BCT treatment and four parenting skills training sessions with their significant others. Participants assigned to the IBT group received 12 individual-based coping skills sessions without their partner present. With regard to child outcomes, the Child Behavior Checklist (CBCL) ${ }^{50}$ was used to assess problem behavior, the Children's Depression Inventory (CDI) ${ }^{51}$ was used to assess depression, and the Revised Children's Manifest Anxiety Scale (RCMAS) ${ }^{52}$ was used to assess anxiety.

The findings show that the children of the PSBCT participants showed greater improvements in problem behavior, depression, and anxiety throughout the 12-month follow-up period than the children of the parents assigned to the other two groups. The children of BCT participants also showed improvements in all of the outcomes immediately after the intervention but the effects for depression and anxiety were not sustained throughout the postintervention follow-up period. Problem behaviors as rated by the mothers and fathers separately using the CBCL showed small effect sizes for PSBCT children at both the 6-month and 12-month follow-up periods when compared to IBT and BCT children. The effect sizes ranged from $0.20-0.27$ for all pairwise comparisons. With regard to depression, small effect sizes were observed for PSBCT children at the 6-month follow-up $(r=0.46)$ and the 12-month follow-up ( $r=0.44)$ when compared to IBT children. Small effect sizes for a reduction in depression were also observed for PSBCT children at the 6-month follow-up $(r=0.25)$ and the 12-month follow-up $(r=0.26)$ when compared to BCT children. When looking at reductions in anxiety, a small effect size was observed for PSBCT children at the 6-month follow-up ( $r=0.43$ ) and the 12-month follow-up $(r=0.41)$ when compared to IBT children. Likewise, a small effect size for a reduction in anxiety was observed for PSBCT children at the 6-month follow-up $(r=0.21)$ and the 12-month follow-up ( $r=0.24)$ when compared to BCT children.

\section{Recommendations for future areas of research}

Despite the large literature that examines the impact of parental substance abuse on children, the findings for this review 
showed that the interventions that have been developed to address this problem would not qualify as an evidence-based program as set forth by the Blueprints registry. The Blueprints registry was created in 1996 at the University of Colorado to identify programs that promote healthy development among youth. To be considered a model program by the Blueprints registry, programs have to demonstrate effectiveness via empirically based research using an experimental design. Additionally, effects must be sustained for at least 12 months after the intervention has ended, and the findings must be successfully replicated. In order to ensure that we had some interventions that could be included in this review, we reduced the postintervention follow-up period from 12 months to 6 months and did not require that the findings had to be replicated.

Consistent with findings from other reviews, very few studies utilized an experimental design and/or did not assess child outcomes. ${ }^{21,53}$ Overall, only four studies met all of the eligibility criteria for this review. Two of the studies ${ }^{48,54}$ that were reviewed for this paper met all of the eligibility criteria with the exception of the last criteria (ie, intervention had to have a significant impact on at least one child outcome) and thus were excluded from this review. However, it should be noted that one of the studies that did not meet this last criteria was a 1-year follow-up of the FOF intervention that was briefly described above. ${ }^{48}$ The main child outcome that was assessed in this particular study was drug use during the previous follow-up period. The authors did not find a significant difference with regard to drug use between the FOF children and the comparison group children and hypothesized that the reason for this may be because of the large number of very young children (younger than 13 years old) in the sample who tend to be less likely to engage in drug use than older children. The findings from the later follow-up study ${ }^{43}$ that was included in this review provide some evidence that this intervention may have had a sleeper effect on the drug use outcomes as the findings from the 12-15-year follow-up showed that the FOF male children had a significant reduction in the risk of developing a substance use disorder. This highlights the importance of incorporating longer-term follow-up periods in studies so that it is possible to assess the impact an intervention may have on various child outcomes over different developmental periods, especially when the findings from the previous studies indicate that there are trends favoring the intervention group.

Another finding from this review showed that all of the studies that met the eligibility criteria for this paper were evaluations of family-based interventions that focused on outcomes for children between the ages of 2 and 16 years. However, addressing the negative impact of prenatal drug exposure on child outcomes is one area that has yet to be fully explored. While there have been numerous interventions designed to reduce prenatal drug exposure and the negative impact this has on birth outcomes, the long-term effects that these interventions may have on the developmental outcomes of the exposed infant in later stages in life have not been assessed. Specifically, the studies that addressed this issue did not meet the eligibility criteria because they did not have a postintervention follow-up assessment point of at least 6 months or greater. Additionally, the outcome of interest was limited mainly to birth outcomes, which were assessed relatively close to the conclusion of the intervention.

Preliminary research suggests that integrated treatment programs are the most effective type of treatment intervention for this population of women. Integrated treatment programs are comprehensive programs that address not just the mother's substance abuse, but also other social, physical, and mental health needs, as well as the needs of the children, which in the case of pregnant mothers, translates to prenatal care. ${ }^{55}$ In a meta-analysis of ten studies that examined the effectiveness of integrated substance abuse treatment in reducing negative birth outcomes, Milligan et $\mathrm{al}^{55}$ found that compared to women who did not participate in an integrated treatment program, the infants of women who did participate in such a program had fewer complications at birth, had higher birth weights, and were more likely to test negative for drugs at birth. However, as mentioned above, the longterm effect of this type of intervention for substance-abusing pregnant women on the developmental outcomes of their children remains unknown and is something that should be examined in future research.

Nurse-Family Partnership (NFP) is one intervention that may be effective in reducing the negative effects of prenatal substance abuse on children over their life course. This intervention did not meet the eligibility requirement of this review because it was targeted toward low-income mothers, so it was possible that many of the mothers who received the intervention did not abuse drugs. Nevertheless, this particular program was identified by the Blueprints registry of evidence-based programs as a model program. The NFP program provides weekly visitations by nurses to high-risk first-time mothers. Visitations start during the prenatal period and last through the first 2 years of the child's life, with the aim of promoting positive health-related behaviors and effective parenting practices. ${ }^{56}$ The findings from randomized controlled trials of this intervention have found that compared 
to the children of women who did not receive the intervention, children whose mothers did receive the intervention were less likely to report using cigarettes, alcohol, and marijuana, and were less likely to report having internalizing disorders such as anxiety and depression at 12 years of age. ${ }^{57}$ When assessing the effect of the program on female girls at the age of 19 years, those whose mothers participated in the NFP program were less likely to have been arrested and convicted than girls whose mothers did not participate in the program ${ }^{58}$ Findings from a recent systematic review suggests that home-visiting programs such as NFP are most effective in improving child outcomes when the intervention is initiated prenatally. ${ }^{59}$

Another area that has been neglected with regard to reducing the negative effects of parental substance abuse on children has to do with disruptions in the family as a result of problem due to parental drug use, involvement in child protective services, or the incarceration of a parent. Just focusing on incarceration, the physical and emotional separation caused by parental incarceration can be detrimental to children, especially in terms of social isolation of the child. Therefore, many researchers have advocated for policies that seek to eliminate or reduce the distance between children and their incarcerated parents. ${ }^{60}$ To address the social isolation that often accompanies parental incarceration, various existing programs connect children with their incarcerated parents. While family visits have been shown to have a positive effect on offenders' behavior, ${ }^{61}$ further research is needed to assess how the practice of children visiting their parents in a correctional setting impacts their mental health and behavior. Also, since many incarcerated parents will resume their role as primary caregiver for their children following their eventual release from prison, there is a need for interventions in correctional settings that prepare parents for this in a way that promotes healthy relationships and developmental outcomes in their children.

Finally, more randomized controlled trials of interventions that target children of substance-abusing parents directly are needed in order to examine what is effective in building resilience in these children long after the intervention has ended. The majority of interventions that have targeted the children directly were delivered in a school setting. However, the evaluations of these school-based interventions did not meet the eligibility criteria because they did not include a long-term postintervention follow-up and/or they were universal-based interventions that did not directly target children of substance-abusing parents. There is some evidence that mentoring programs may be able to provide a stabilizing influence for children who experience constant disruptions in their family life. The Big Brothers Big Sisters of America (BBBSA) is such a mentoring program that has been identified by the Blueprints registry as a promising intervention for at-risk children. This particular program matches adult volunteer mentors with at-risk children. Mentors and their matched children meet with each other for at least 3-5 hours a week. A case manager identifies goals that the mentor/mentee should seek to address throughout their time spent together such as learning new skills, improving academic performance, and general hygiene. In an experimental study of the BBBSA program, Grossman and Tierney found that youth randomly assigned to the BBBSA program were significantly less likely to use drugs, engage in truancy, and hit someone than the control group, who were put on the waiting list for the BBBSA for 18 months. ${ }^{62}$

\section{Conclusion}

While parental substance abuse may contribute to physical and mental health and behavioral problems in children, findings from the studies included in this review suggest that these problems can be mitigated by improving the functioning of the family. Specifically, findings from randomized controlled trials of programs that target substance-abusing parents suggest that interventions that target parenting practices in addition to substance abuse show the most promise for improving family functioning, and subsequently, the health and well-being of children. ${ }^{42-45}$ However, these findings should be treated as very preliminary due to the limited number of studies that were found to meet all of the eligibility criteria in this review. Thus, a substantial amount of research is still needed before we can truly identify effective interventions for children affected by parental substance abuse. Furthermore, since the lives of children of substance-abusing parents are often marked by instability, it is also important to find ways to build resilience within the children in order to help mitigate the negative impact that parental substance abuse and its related consequences have on their lives. While mentoring programs such as BBBSA show great promise in helping children successfully cope with the negative impacts on their lives and development, further research using experimental designs is needed to identify and assess other successful interventions that can provide additional help to these children.

\section{Acknowledgments}

We would like to thank William Burdon for providing substantive suggestions for improvement, and Kris Langabeer for editorial review. We would also like to thank Priyanka Mehta for assistance with the literature search. 


\section{Disclosure}

The authors report no conflicts of interest in this work.

\section{References}

1. Substance Abuse and Mental Health Services Administration. The NSDUH Report: Children Livng with Substance-Dependent or Substance-Abusing Parents: 2002 to 2007. Rockville, MD: Substance Abuse and Mental Health Services Administration; 2009.

2. Peleg-Oren N, Teichman M. Young children of parents with substance use disorders (SUD): a review of the literature and implications for social work practice. $J$ Soc Work Pract Addict. 2006;6(1-2):49-61.

3. Kilpatrick DG, Acierno R, Saunders B, Resnick HS, Best CL, Schnurr PP. Risk factors for adolescent substance abuse and dependence: data from a national sample. J Consult Clin Psychol. 2000;68(1):19-30.

4. Keegan J, Parva M, Finnegan M, Gerson A, Belden M. Addiction in pregnancy. J Addict Dis. 2010;29(2):175-191.

5. Behnke M, Smith VC; Committee on Substance Abuse; Committee on Fetus and Newborn. Prenatal substance abuse: short- and long-term effects on the exposed fetus. Pediatrics. 2013;131(3):e1009-e1024.

6. Nguyen D, Smith LM, Lagasse LL, et al. Intrauterine growth of infants exposed to prenatal methamphetamine: results from the infant development, environment, and lifestyle study. $J$ Pediatr. 2010;157(2):337-339.

7. Smith LM, LaGasse LL, Derauf C, et al. Prenatal methamphetamine use and neonatal neurobehavioral outcome. Neurotoxicol Teratol. 2008;30(1):20-28

8. LaGasse LL, Wouldes T, Newman E, et al. Prenatal methamphetamine exposure and neonatal neurobehavioral outcome in the USA and New Zealand. Neurotoxicol Teratol. 2011;33(1):166-175.

9. Bandstra ES, Morrow CE, Mansoor E, Accornero VH. Prenatal drug exposure: infant and toddler outcomes. J Addict Dis. 2010;29(2):245-258.

10. Lewis BA, Singer LT, Short EJ, et al. Four-year language outcomes of children exposed to cocaine in utero. Neurotoxicol Teratol. 2004;26(5):617-627.

11. Bada HS, Das A, Bauer CR, et al. Impact of prenatal cocaine exposure on child behavior problems through school age. Pediatrics. 2007;119(2):e348-e359.

12. Minnes S, Singer L, Min MO, Wu M, Lang A, Yoon S. Effects of prenatal cocaine/polydrug exposure on substance use by age 15. Drug Alcohol Depend. 2014;134:201-210.

13. McKeganey N, Barnard M, McIntosh J. Paying the price for their parents' addiction: meeting the needs of the children of drug-using parents. Drugs Educ Prev Policy. 2002;9(3):233-246.

14. Stanger C, Dumenci L, Kamon J, Burstein M. Parenting and children's externalizing problems in substance-abusing families. $J$ Clin Child Adolesc Psychol. 2004;33(3):590-600.

15. Gershoff ET. Corporal punishment by parents and associated child behaviors and experiences: a meta-analytic and theoretical review. Psychol Bull. 2002;128(4):539-579.

16. Miner JL, Clarke-Stewart KA. Trajectories of externalizing behavior from age 2 to age 9: relations with gender, temperament, ethnicity, parenting, and rater. Dev Psychol. 2008;44(3):771-786.

17. Hien D, Honeyman T. A closer look at the drug abuse-maternal aggression link. J Interpers Violence. 2000;15(5):503-522.

18. Fals-Stewart W, Kelley ML, Fincham FD, Golden J, Logsdon T. Emotional and behavioral problems of children living with drug-abusing fathers: comparisons with children living with abusing and nonsubstance-abusing fathers. J Fam Psychol. 2004;18(2):319-330.

19. Bank L, Forgatch MS, Patterson GR, Fetrow RA. Parenting practices of single mothers: mediators of negative contextual factors. J Marriage Fam. 1993;55(2):371.

20. Arnold DS, O'Leary SG, Wolff LS, Acker MM. The Parenting Scale: a measure of dysfunctional parenting in discipline situations. Psychol Assess. 1993;5(2):137-144.
21. Barnard M, McKeganey N. The impact of parental problem drug use on children: what is the problem and what can be done to help? Addiction. 2004;99(5):552-559.

22. Messina N, Jeter K. Parental methamphetamine use and manufacture: child and familial outcomes. J Public Child Welf. 2012;6(3):296-312.

23. Manning T. Drug labs and endangered children. FBI Law Enforc Bull. 1999;68(7):10-14.

24. Grant P, Bell K, Stewart D, Paulson J, Rogers K. Evidence of methamphetamine exposure in children removed from clandestine methamphetamine laboratories. Pediatr Emerg Care. 2010;26(1):10-14.

25. Dunn MG, Tarter RE, Mezzich AC, Vanyukov M, Kirisci L, Kirillova G. Origins and consequences of child neglect in substance abuse families. Clin Psychol Rev. 2002;22(7):1063-1090.

26. Meyer AS, McWey LM, McKendrick W, Henderson TL. Substance using parents, foster care, and termination of parental rights: the importance of risk factors for legal outcomes. Child Youth Serv Rev. 2010;32(5):639-649.

27. Dakof GA, Cohen JB, Henderson CE, et al. A randomized pilot study of the Engaging Moms Program for family drug court. J Subst Abuse Treat. 2010;38(3):263-274.

28. Newton RR, Litrownik AJ, Landsverk JA. Children and youth in foster care: disentangling the relationship between problem behaviors and number of placements. Child Abuse Negl. 2000;24(10):1363-1374.

29. Smith DK, Stormshak E, Chamberlain P, Bridges Whaley R. Placement disruption in treatment foster care. J Emot Behav Disord. 2001;9(3):200-205.

30. National Center on Addiction and Substance Abuse. Behind Bars II: Substance Abuse and America's Prison Population. New York, NY: Columbia University; 2010.

31. Murray J, Murray L. Parental incarceration, attachment and child psychopathology. Attach Hum Dev. 2010;12(4):289-309.

32. Murray J, Loeber R, Pardini D. Parental involvement in the criminal justice system and the development of youth theft, marijuana use, depression, and poor academic performance. Criminology. 2012;50(1):255-302.

33. Roettger ME, Swisher RR, Kuhl DC, Chavez J. Paternal incarceration and trajectories of marijuana and other illegal drug use from adolescence into young adulthood: evidence from longitudinal panels of males and females in the United States. Addiction. 2011;106(1):121-132.

34. Dallaire DH, Ciccone A, Wilson LC. Teachers' experiences with and expectations of children with incarcerated parents. JAppl Dev Psychol. 2010;31(4):281-290.

35. Cho R. Maternal incarceration and children's adolescent outcomes: timing and dosage. Soc Serv Rev. 2010;84(2):257-282.

36. Cho RM. The impact of maternal imprisonment on children's educational achievement results from children in Chicago public schools. J Hum Resour. 2009;44(3):772-797.

37. Huebner BM, Gustafson R. The effect of maternal incarceration on adult offspring involvement in the criminal justice system. J Crim Justice. 2007;35(3):283-296.

38. Nesmith A, Ruhland E. Children of incarcerated parents: challenges and resiliency, in their own words. Child Youth Serv Rev. 2008;30(10):1119-1130.

39. Hagan J, Dinovitzer R. Collateral consequences of imprisonment for children, communities, and prisoners. Crime Justice. 1999:121-162.

40. Geller A, Garfinkel I, Western B. Paternal incarceration and support for children in fragile families. Demography. 2011;48(1):25-47.

41. Cohen J. Statistical Power Analysis for the Behavioral Sciences. 2nd ed. Hillsdale, NJ: L Erlbaum Associates; 1988.

42. Dawe S, Harnett P. Reducing potential for child abuse among methadone-maintained parents: results from a randomized controlled trial. J Subst Abuse Treat. 2007;32(4):381-390.

43. Haggerty KP, Skinner M, Fleming CB, Gainey RR, Catalano RF. Long-term effects of the Focus on Families project on substance use disorders among children of parents in methadone treatment. Addiction. 2008;103(12):2008-2016. 
44. Kelley ML, Fals-Stewart W. Couples- versus individual-based therapy for alcohol and drug abuse: effects on children's psychosocial functioning. J Consult Clin Psychol. 2002;70(2):417-427.

45. Lam WK, Fals-Stewart W, Kelley ML. Effects of Parent Skills Training with Behavioral Couples Therapy for alcoholism on children: a randomized clinical pilot trial. Addict Behav. 2008;33(8):1076-1080.

46. Goodman R. The Strengths and Difficulties Questionnaire: a research note. J Child Psychol Psychiatry. 1997;38(5):581-586.

47. Goodman R. Psychometric properties of the strengths and difficulties questionnaire. J Am Acad Child Adolesc Psychiatry. 2001;40(11):1337-1345.

48. Catalano RF, Gainey RR, Fleming CB, Haggerty KP, Johnson NO. An experimental intervention with families of substance abusers: one-year follow-up of the focus on families project. Addiction. 1999;94(2):241-254.

49. Jellinek MS, Murphy JM. The recognition of psychosocial disorders in pediatric office practice: the current status of the pediatric symptom checklist. J Dev Behav Pediatr. 1990;11(5):273-278.

50. Achenbach TM, Ruffle TM. The Child Behavior Checklist and related forms for assessing behavioral/emotional problems and competencies. Pediatr Rev Am Acad Pediatr. 2000;21(8):265-271.

51. Kovacs M. The Children's Depression, Inventory (CDI). Psychopharmacol Bull. 1985;21(4):995-998.

52. Reynolds CR. Concurrent validity of "What I think and feel:" the Revised Children's Manifest Anxiety Scale. J Consult Clin Psychol. 1980;48(6):774-775.

53. Bröning S, Kumpfer K, Kruse K, et al. Selective prevention programs for children from substance-affected families: a comprehensive systematic review. Subst Abuse Treat Prev Policy. 2012;7(1):23.
54. Luthar SS, Suchman NE, Altomare M. Relational Psychotherapy Mothers' Group: a randomized clinical trial for substance abusing mothers. Dev Psychopathol. 2007;19(1):243-261.

55. Milligan K, Niccols A, Sword W, Thabane L, Henderson J, Smith A. Birth outcomes for infants born to women participating in integrated substance abuse treatment programs: a meta-analytic review. Addict Res Theory. 2011;19(6):542-555.

56. Olds DL. Home visitation for pregnant women and parents of young children. Arch Pediatr Adolesc Med. 1992;146(6):704-708.

57. Kitzman HJ, Olds DL, Cole RE, et al. Enduring effects of prenatal and infancy home visiting by nurses on children: follow-up of a randomized trial among children at age 12 years. Arch Pediatr Adolesc Med. 2010;164(5):412-418.

58. Eckenrode J, Campa M, Luckey DW, et al. Long-term effects of prenatal and infancy nurse home visitation on the life course of youths: 19-year follow-up of a randomized trial. Arch Pediatr Adolesc Med. 2010;164(1):9-15.

59. Peacock S, Konrad S, Watson E, Nickel D, Muhajarine N. Effectiveness of home visiting programs on child outcomes: a systematic review. BMC Public Health. 2013;13(1):17.

60. Block K, Potthast M. Girl Scouts Beyond Bars: facilitating parent-child contact in correctional settings. Child Welfare. 1998;77(5):561-578.

61. Bales WD, Mears DP. Inmate social ties and the transition to society: does visitation reduce recidivism? J Res Crime Delinquency. 2008;45(3):287-321.

62. Grossman JB, Tierney JP. Does mentoring work? An impact study of the Big Brothers Big Sisters Program. Eval Rev. 1998;22(3):403-426.
Substance Abuse and Rehabilitation

\section{Publish your work in this journal}

Substance Abuse and Rehabilitation is an international, peer-reviewed, open access journal publishing original research, case reports, editorials, reviews and commentaries on all areas of addiction and substance abuse and options for treatment and rehabilitation. The manuscript management system is completely online and includes a very quick and fair

\section{Dovepress}

peer-review system. Visit http://www.dovepress.com/testimonials.php to read real quotes from published authors. 